\title{
A Methodology For Developing And Testing The Effectiveness Of Using Entrepreneurial Skills And Supply-Side Innovations To Improve The Performance Of Small And Medium Sized Enterprise
}

Nkanta Frank Ekanem, (Email: fekanem@howard.edu), Howard University

\begin{abstract}
The study identified and took stock of the supply-side resources, which can be harnessed for entrepreneurial development in Nigeria. Although there is a considerable gender gap in entrepreneurial development, the study reveals that there is a considerable desire for private sector-driven entrepreneurial development, supported by a large pool of highly educated and relatively young entrepreneurs, who may be responsible for the enormous growth in the number of new businesses formed since 1990. Future studies and government empowerment policies should be directed to addressing the problem of the limited management and technological orientations identified in this study to enable funding initiatives to be beneficial.
\end{abstract}

\section{INTRODUCTION}

E

ntrepreneurial development is not just developing new business ideas and taking steps to implement such ideas. It is like the proverbial sowing of the seed. It calls for a healthy seed, a fertile soil and a patient farmer to tend the young plant from the point the leaves begin to grow until the plant bears fruits. Just as the farmer has to work patiently and regularly on the field in every detail, including for example applying fertilizer in the right amount, the entrepreneur must attend to his/her business from formation until it grows to maturity. Entrepreneurial development requires several skills, such as management and technological orientation. It calls for perseverance even in the face of daunting frustration, and failure. It requires a unique institutional environment that would accommodate change. Since most small and medium-sized enterprises cannot survive on their own without outside assistance, intervention policies are necessary for entrepreneurial development. These intervention innovations should not be a one-time event, but should come in several forms and must come in the right amount, and over a period needed to ensure a successful enterprise.

This paper describes the stock of the supply-side resources needed to ensure successful entrepreneurial development in Nigeria. These include owner-specific skills, institutional environments, and government intervention policies herein after called Supply-Side Innovation Services. We describe the amount and quality of the resources available for entrepreneurial development and the type of intervention policy needed to ensure success. We call for prompt elimination of all environmental constraints facing entrepreneurship.

\section{OWNER-SPECIFIC ENTREPRENEURIAL RESOURCES}

The model assumes that there is a core of entrepreneurs with business ideas, who are committed to transforming those business ideas into a reality. The entrepreneur's commitment can be measured by how long this entrepreneur has been in business; and how much he or she has invested to develop his or her skills and the business. 
The entrepreneur is driven by the profit motive and the desire to be successful. We call this private sector activism, or "primacy of markets in development" (Goldin, et al. 2002).

The model also assumes that there is an element of technological and management orientation. It also call for a culture which embraces commitment to good quality products and services and sound financial management, control and transparency.

Also included among these traits are perseverance and the will and determination to succeed in the face of challenges, as well as the willingness to invest in human capital development, (Daly, 2002), and financial commitment. We also assume that there is a unique institutional arrangement, inside and outside of the enterprise that can bring about most entrepreneurial development. Edgcomb and Cawley, (1994) provide a detailed treatment of one aspect of institutional environment. Institutional environment includes all aspects of the internal structure of the enterprise, corporate policy, employee relations, mission, vision, financial management and control, technological capability, as well as inter-industry relations. Intervention innovations can only be effective if the institutional environment of an enterprise is flexible and responsive to absorb change. Institutional environment here is defined to include the vision of the enterprise, management structure and the type and quality of the resources at the disposal of the enterprise. Similarly, intervention can only be effective if the enterprise has a plan to make use of such intervention, (OECD, 1991).

The concept of owner-specific trait and behavioral norms is sometimes indistinguishable from institutional process. Two examples are vision and technology orientation. It is difficult, and probably impossible to draw a distinction between vision and technological orientation in institutional and owner-specific process. Vision is an institutional or owner-specific trait that expresses the fundamental ideas that drive an enterprise from the present, where most of the operating environment is known into the future with numerous unknown variables. The institution is as visional as the owner of the enterprise. Technological orientation is another owner-specific and institutional trait, and like vision, it permeates all facets of organization and facilitates learning, and adaptation and change, (Edgcomb and Cawley,1994). This model assumes that there is an entrepreneur, which is committed to running a successful business but needs a congenial operating environment.

The success of this model calls for three elements. The first is the dedication and commitment of this entrepreneur to be successful. The second is institutional flexibility, which would enable the enterprise to absorb governmental intervention and other innovations of change, including technology diffusion (Biggs 1999). The third is government's willingness to remain committed to bringing about change and entrepreneurial success.

\section{INTERVENTION POLICIES}

Although highly handicapped by limited budgetary problems and poor quality of social infrastructure, the model assumes the existence of activist public sector with a commitment, not through direct investment, or ownership but through empowerment of private sector activism. Institutional environment can be improved in many ways. These include staff development and training, technology development, cultural and organizational reforms. Although small and medium-sized enterprises in Nigeria seem to place the highest priority on financial assistance, we stress an overhaul of the institutional arrangement to bring about a free enterprise culture and a capitalistic spirit, to bring about effective financial and technological intervention. We also stress that financial assistance be provided to enterprises which best can utilize them. They can best benefit from intervention policies when institutional constraints are removed to promote supply-side efficiency.

The model does not envisage privatization, which involves total divestiture of ownership and management of an enterprise. However, it envisages a sustained commitment to the success of the private sector through empowerment rather than excessive regulation and taxation. We cannot rely on "more statist approach of the 1950's and 1960's, nor the more minimal-government free market approach that dominated policy debate in the 1980s and early 1990s, but on the private sector initiative, with effective government partnership, to provide the governance framework, and the necessary infrastructure" (Goldin et al. 2002). This culture is urgently needed in Nigeria. Another intervention is "institution building, including appropriate financial and legal institution" (Daly 2002). 
Two types of Business Development Services are usually considered, namely the demand-side and the supply-side services, although the actual difference between the two are usually not made quite clear. The supply-side BDS is considered in this paper because of the writer's belief that enterprise performance can best be achieved through empowerment through enabling legislation and public services needed by the private sector for wealth creation. There are several parts of the model. One can deal with the model piece by piece or as one complex process. We choose to treat it as a complex process, consisting of the institutional process, and all forms of empowerment assistance.

Intervention assistance can be direct or indirect assistance. They can be given in the form of an enabling environment for private sector success. Several types of direct assistance are often considered. Although financial assistance is often rated with the highest priority in Nigeria, assistance includes several forms of capacity building, such as skills acquisition, technology enhancement, business counseling, record keeping and performance monitoring and reporting. This study does not consider specific direct governmental assistance or government-generated resources, but discusses the complex issues of institutional problems, such as governmental policies needed to ensure a level playing field, quality of social infrastructure, and other problems. It stresses the importance of timing and the proper sequencing of intervention. It also notes that many small and medium sized enterprises are constrained by institutional problems, such as disinclination to embrace change, and hence the need for government to play an active role in bringing about a change in such culture.

\section{CONCEPTUAL ISSUES}

This section is devoted to two issues. The first is the description of the desired environmental and behavioral norms that are required of all stakeholders in this model. The second is the description of standard for the measurement of enterprise performance. Environmental and behavioral norms can be looked at as a layer in a complex tapestry made up of the functions of the government, the enterprise and their owners.

The functions of government include laws and regulations, which are required to ensure that there is a level playing field for businesses to survive. Other governmental functions consist of direct inputs, such as financial assistance, public services such as power, water and communications, training programs, and equipment. Nigerians have a long history of publicly owned enterprises which produce services which are marketed at subsidized prices. On the other hand, they harbor a deep mistrust and disgust for individual business owners, especially small business owners. For this reason, it is not surprising that ongoing attempt to embrace divestiture from publicly owned enterprises does not include a plan to extend immediate financial support for small and medium-sized enterprises. The reason for this is partly understandable; Nigerians, individuals or corporate enterprises, are not trusted by financial institutions for being able or willing to pay back their debt. . For this reason, no bank or lending institution is willing to lend money to any Nigerian business owner, unless he or she has tangible assets worth, perhaps twice the amount, which the institution is asked to lend. However, unless we are ready to cut our nose to spite our face, we must soon begin to consider doing those seemingly impossible things. The question however is, if Nigerians are willing to invest billions of dollars in publicly-owned enterprises, which are mostly mismanaged, why are they so mindful of protecting millions of dollars in indirect support to facilitate the growth of micro-, small and medium-owned enterprises.

To determine effectiveness of any policy innovation, we must define the standard upon which the innovation can be measured. There are several possible criteria to measure the effectiveness of the supply-side development services. These include growth in gross sales, employment growth, survival rate, technology orientation, ability to borrow and use money prudently, improved record keeping, record storage and retrieval, etc. The measurement criteria selected for the purpose of this study are growth of gross sales, employment growth, technology and management orientation and, growth in start-up capital.

\section{THE SAMPLE}

This study is based on a sample of 190 small and medium-sized enterprises located in seven states in Nigeria. Enterprises included in the study were not selected at random, but were interviewed by the author and students registered in an undergraduate course, Entrepreneurial Development for graduating seniors at the University of 
Calabar, Nigeria. Although the sample was not drawn at random, students were given specific instructions on the data collection exercise. These include; instruction to interview only owners who are willing to participate in the survey; not to volunteer answers to any question, but to help the respondents to understand the question; to ensure consistency in the answers provided by the respondents and to ensure that all questions are answered. Although enterprises in Akwa Ibom and Cross River States were over-represented, the nonrandom selection of the sample is not expected to affect the usefulness of the data collected. For this reason, no attempt is made to make any inferences on the state distribution of the enterprises. It is therefore possible to calculate average gross sales, average employment and average start-up capital by state, by industry, by gender, by tenure of enterprises, and by owner and selected management criteria.

\section{STATISTICAL ANALYSIS AND PERFORMANCE MEASUREMENT}

First, we choose the objective variable $Y_{P}$ for measuring the performance of the relevant enterprise. Next, we choose the supply-side skills and innovation variables, $X_{i}=1$, when the relevant supply-side innovation or skills assumed to be consistent with significant improvement in the performance of the enterprise; $X_{j}=1$, when the supplyside skills and innovations considered to be relevant to high performance of the enterprise do not exist. Using these definitions, we specify the following theoretical assumptions:

$\partial \mathrm{Y}_{\mathrm{P}} / \partial \mathrm{X}_{\mathrm{i}}>\partial \mathrm{Y}_{\mathrm{P}} / \partial \mathrm{X}_{\mathrm{j}}$ for all $\mathrm{X}_{\mathrm{i}}, \mathrm{X}_{\mathrm{j}}=1$

$\mathrm{X}_{\mathrm{i}}$ represents a matrix consisting of a host of independently defined owner-specific and institutional variables which are consistent with high performance. Interaction variables which describe the joint effect of institutional and owner-specific traits are also included. $\mathrm{X}_{\mathrm{j}}$ represents a matrix of similarly defined owner-specific and institutional variables which are non-conducive to improved performance. These include lack of transparency, less than High School education, limited management and technological skills, and a disinclination to learn or adapt to change. Some statistical analyses were conducted to match owner- and institutional characteristics with performance. The parameters for measuring performance include gross sales, start-up capital and employment. The instruments by which performance are measured include gender, age and education of owner; and institutional variables include tenure, industry, size of enterprise, legal form, technological and management orientations. The model assumes that gross sales, start-up capital and employment are higher in enterprises whose owners have certain owner-specific characteristics and management skills.

The data base shows that gross sales, start-up capital and employment are higher in large enterprises, and in enterprises in which the owners possess unique traits, depending upon the type of management intervention used in the enterprise. Table 1 shows the distribution of enterprises in the sample and their responses to the questionnaire. The responses are given in percent for each owner, firm characteristics and policy instruments indicated. Tables 2 and 3 show the performance of the enterprises for given owner and firm characteristics, and type of management intervention policy. Table 4 shows the results of the interactive analysis of the joint effect of owner-specific and intervention instruments.

The discussion of the results consists of two parts. The first part deals with the distribution of the enterprises around selected owner, firm characteristics. This analysis is intended to show that certain owner-specific traits are more likely to produce greater performance and ought to be encouraged and facilitated. The second part deals with the analysis of the performance of enterprises following the application of selected standard management methods. We begin with the distribution of firms by owner characteristics, such as gender, age, and education of owners; and firm characteristics such as tenure, legal form, the number of employees, and the source of capital.

The data show that $76.8 \%$ of enterprises are male-owned compared to $23.1 \%$ by females; owners of $34.2 \%$ of enterprises are aged 30-40 years, followed by $41-45$ year-old owners with $25.3 \%$. Owners of $55.0 \%$ of the enterprises are college educated, while $17.9 \%$ are educated at Diploma/Technical levels, and 16.8\% are educated at High School levels. The distribution of enterprises along selected firm characteristics are source of capital, legal form and tenure. $53.7 \%$ obtain capital from personal savings, $32.6 \%$ others obtain funding from family/ personal loans, while $11.6 \%$ obtain start-up capital from commercial banks. $68.4 \%$ of the enterprises are sole proprietors, while $21.6 \%$ are limited 
liability companies. The sizes of enterprises are as follows: $16.3 \%$ less than 3 employees; $28.9 \%$ 3-5 employees; 24.2\% 6-10 employees; $20.5 \%$ more than 10 employees and about $10.0 \%$ have no employees.

The data reveal areas of strength and weakness. These strengths and weakness cut across owner and institutional characteristics. The data show an enormous gender gap in entrepreneurial development, which must be closed. It also shows that male-owned enterprises outperform female-owned enterprises in gross sales. An attempt is made in the paper to develop a strategy to increase the performance of female-owned enterprises. Enterprises with six or more employees also outperform enterprises with fewer employees. Enterprises formed before 1980, that is to say, enterprises with long tenure, and those whose owners are educated beyond High School outperform their counterparts in gross sales. We use tenure as an instrument for measuring entrepreneurial perseverance and a platform for acquiring experience and gaining efficiency in just the same way as education does. In addition, enterprises in the petroleum sector, medical centers and in transportation report relatively more in gross sales than enterprises in other sectors.

However, the data reveal very little technological orientation and knowledge of, and use of known management methods. For instance, $26.3 \%$ hold regular management meetings to review past week's performance and plan future strategy. $23.1 \%$ have definite plans to improve product quality, and $26.8 \%$ maintain some form of operating budget. On the other hand, $62.6 \%$ consider financial assistance as their highest priority; $13.1 \%$ list technical assistance and $23.7 \%$ list counseling, monitoring and management assistance to be their highest priority. Some of these results are blamed on the undue aggregation of the data, which include micro-enterprises, which neither understand, nor have the capability of understanding or making use of such management methods. The severity of such anomaly is reduced when micro-enterprises are eliminated. There is a strong expectation that the increasing rate of university educated business owners in Nigeria will accelerate the process of "integrating new technologies with traditional economic activities" and speed up that technological orientation, (Bhalla, et al., 1991). Due to the increasing application of information and communication technology to management, the scope of technology is defined to include management process, (Daly, 2002).

The implications of the statistics in Table 1 are very significant in terms of the behavior of Nigerian small and medium sized enterprises. This Table shows that only $23.1 \%$ of our respondents have any plans to improve the quality of their products and services. Given that the quality of most of the products is low in the first place, it should be obvious to the business owners that the only way to maintain a sustained demand for their products or services is to improve the quality of their products or services. Although only $10 \%$ of the respondents give a high priority to a plan to use government financial assistance to investigate the means of improving product quality, these respondents appear to be among those that report the highest gross sales compared to those, which do not put product quality improvement at the top of their concern. The significance of high product quality can be seen in more than two aspects, namely the marketability and the consumability of the product. It is obvious that most Nigerian enterprises are yet to fully understand that it is easier to market as it is safe to consume high quality product.

Only $26.8 \%$ and $31.0 \%$, respectively realize the importance of budgeting and planning as important aspects of business management. Budgeting and planning are crucial aspects of a visionary enterprise. Just as planning helps to define the vision of an enterprise, budgeting drives ideas along the course defined in the vision, and the failure to grapple with these philosophies leaves an enterprise groping about in uncertainties. In the same manner, low scores on the conduct of regular management training in which more skills are learnt, and regular management meetings to review past weeks' activities and plan for subsequent weeks' performance leaves room for employee inefficiency and supervisory ineptitude.

Table 1 also shows the distribution of enterprises by type of government assistance desired, and their ranking of how they would use any government assistance. It would not necessarily be wrong to consider a situation where overwhelming number of enterprises consider financial assistance as the most important supply-side assistance they wish to get from government, while only $13 \%$ rank technical assistance high on the list of their need in the 21 st century global environment. Of course it would be wrong if the enterprises which receive such financial assistance cannot put such financial assistance into effective use to increase the performance of their businesses. Table 1 shows that $23.7 \%$ of the enterprises, which rank management assistance high on the list of their choice of supply-side assistance, report higher gross sales growth as a result of their choice of that type of assistance. Table 3 provides a 
detailed list of selected management method adopted by various enterprises and compares their performance in terms of gross sales and employment growth.

\section{INSTRUMENT INTERACTION}

We realize that enterprises having certain characteristics out-perform their counterparts without such characteristics in terms of sales growth, start-up capital and employment generation, than their counterparts without such characteristics. These characteristics are owners' personal traits, such as gender, age and education of owner. Other owner-specific characteristics are management skills, technology orientation and their choice of how they make use of government intervention instrument. We also realize that adoption of certain management decisions also enables some enterprises to increase their performance in terms of sales growth, employment generation and start-up capital. For these reasons, it was considered necessary to investigate the joint effect of owner-specific traits, such as age and gender of owner; management methods, and institutional characteristics. Owner and institutional situations considered are age and gender of owner; scale of operation, technological and management orientations. The interaction analysis was conducted between the dummy variables for large enterprises, and the dummy variables for technology and management orientation. Similarly average gross sales, average start-up capital and average employment were calculated for the interaction variables for female-owned enterprises, and the dummy variables for management and technology orientation. The interaction between gender and management dummy variables allows us to show that female-owned enterprises can increase their performance, given the right amount of management and, or technological skills. Through this method we discover that female-owned enterprises can compete favorably in performance with their male-owned counterpart, through the injection of the right amount of technological and management skills. Similarly, enterprises whose owners prefer financial assistance to other supply-side intervention assistance, report less impressive performance compared to enterprises that use technological, monitoring, counseling and management skills development and other supply-side intervention instruments.

The result of the interaction analysis in Table 4 can be compared with Table 1 (e), 1(f) and Table 2. Table 1(e) shows that enterprises which obtain government financial assistance, but do not make an effective use of such assistance report relatively lower gross sales than otherwise. However, Table 4 shows that enterprises, which decide to use government financial assistance to acquire improved management and technological capability, can improve their performance considerably. In the same manner, female-owned enterprises, which otherwise report lower gross sales, start-up capital and employment, considerably improve their performance by using financial assistance to acquire improved management and technological capability.

\section{CRITERIA FOR SELECTING ENTERPRISES FOR DEVELOPMENT ASSISTANCE INTERVENTION}

It has been stressed above that grant assistance should be given to enterprises, which possess the capability to utilize such assistance productively, (Biggs, 1999). It is obvious that policy statements in such broad language could pose serious problem of subjectivity in the implementation. The objective process of selection could be long and tedious. We begin by selecting among enterprises, which produce services that are clearly "profitable" or not "profitable" from the point of view of the enterprise, (Biggs, 1999). The Biggs' model further subdivides these enterprises into those which produce socially beneficial goods or services, and those which do not, and recommends that public intervention assistance be given to enterprises which generate social economic benefits but are not profitable and hence unattractive to the private sector investment. We propose selection of enterprises for public intervention assistance on the basis of clear, objective and measurable national goals. Here are a few examples of such national policy goals:

\footnotetext{
- Technological development potential

- $\quad$ Quality improvement

- $\quad$ Target export growth

- $\quad$ Minimum value-added

- $\quad$ Community development and involvement

- $\quad$ Productivity growth

- $\quad$ Minimum employment generation
} 
- $\quad$ Target investment growth

- Transparency, accountability and Governance

Each of these goals could be individually and severally ranked by the national authority and the one that scores the highest on the scale should be the first to be grant-supported. Apart from meeting these national goals, the owners or investors in each enterprise should be required to make minimum commitment in the business to qualify for intervention assistance. However, an enterprise may be allowed a waiver on the requirement of heavy financial investment in the enterprise, if it more than meets any one of other important national goals as may be determined by government. These may include potential for rural poverty eradication, quality improvement, target export generation, or transparency, accountability and governance. On its part, the government must also exercise utmost transparency in its selection of enterprises for development assistance intervention and not allow it judgment to be heavily influenced by political ideology or tribal consideration.

\section{CONCLUSIONS}

This study takes stock of the supply-side resources, which can be harnessed for entrepreneurial development in Nigeria. These resources are owner-specific, such as age and education of owner; and institution-specific, such as scale of operation, technology and management orientation. The Nigerian small and medium sized enterprises face serious challenges, being mostly sole proprietorship, formed mostly with capital from personal saving and family loans, and very little participation by established banking and funding institutions. The study reveals that, although there is a considerable desire for private sector-driven entrepreneurial development, as measured by the pool of highly educated and relatively young entrepreneurs, who may be responsible for the enormous growth in the number of new businesses formed since 1990, there is a dearth of skilled management and technology orientation. However, it is important and our recommendation that any intervention or empowerment policy be based on the institutional transparency and ability to absorb such interventions, and adapt to change.

We urge that government takes steps to encourage an aggressive management and technology training, using the pool of highly educated individuals who are eager to become business owners. We also urge that government and the established banking institutions, not only play a sustained role in providing financial assistance to small and medium sized enterprises, but stipulate a procedure for monitoring their performance and encouraging these institutions to use such financial assistance in acquiring technological and managerial skills. Although very little management and technological orientation is evident, there is however, a tremendous potential for many of these enterprises to improve their performance, if many of the supply-side constraints are eliminated. The study also reveals that there is a considerable gender gap in entrepreneurial development that must be closed, if women-owned enterprises are expected to achieve their full potentials in employment and income generation.

Table 1: Distribution (\%) Of Enterprises By Selected Characteristics

(a) Age and Gender

\begin{tabular}{|c|c|c|c|c|c|c|c|}
\hline \multicolumn{2}{|c|}{ Gender } & \multicolumn{7}{|c|}{ Age of Owner in Years } \\
\hline Male & Female & $<\mathbf{3 0}$ & $\mathbf{3 0 - 4 0}$ & $\mathbf{4 1 - 4 5}$ & $\mathbf{4 6 - 5 0}$ & $\mathbf{5 1 - 6 5}$ & $>\mathbf{6 5}$ \\
\hline 76.8 & 23.1 & 13.7 & 34.2 & 25.3 & 14.7 & 10.5 & 1.6 \\
\hline
\end{tabular}

(b) Education and Enterprise

\begin{tabular}{|c|c|c|c|c|c|c|c|c|}
\hline \multicolumn{4}{|c|}{ Education of owner } & \multicolumn{4}{c|}{ Tenure of enterprise } \\
\hline $\begin{array}{c}\text { <High } \\
\text { school }\end{array}$ & High School & $\begin{array}{c}\text { Diploma/ } \\
\text { technical }\end{array}$ & $\begin{array}{c}\text { University } \\
\mathbf{1 9 8 0}\end{array}$ & $\begin{array}{c}\text { Before } \\
\mathbf{1 9 8 5}\end{array}$ & $\begin{array}{c}\mathbf{1 9 8 0}- \\
\mathbf{1 9 9 0}\end{array}$ & $\begin{array}{c}\mathbf{1 9 8 6}- \\
\mathbf{1 9 9 5}\end{array}$ & $\mathbf{1 9 9 1 - 1 9 9 5}$ & After \\
\hline 10 & 16.8 & 17.9 & 55.3 & 7.4 & 14.7 & 23.1 & 18.9 & 35.8 \\
\hline
\end{tabular}

(c) Capital and Enterprise

\begin{tabular}{|c|c|c|c|c|c|c|}
\hline \multicolumn{3}{|c|}{ Legal form of enterprise } & \multicolumn{4}{c|}{ Source of capital } \\
\hline $\begin{array}{c}\text { Sole proprie- } \\
\text { torship }\end{array}$ & Partner-ship & $\begin{array}{c}\text { Limited } \\
\text { liability }\end{array}$ & $\begin{array}{c}\text { Personal } \\
\text { saving }\end{array}$ & $\begin{array}{c}\text { Personal/ } \\
\text { family }\end{array}$ & $\begin{array}{c}\text { Commer- } \\
\text { cial bank }\end{array}$ & Other \\
\hline 68.4 & 7.9 & 21.6 & 53.7 & 32.6 & 11.6 & 2.1 \\
\hline
\end{tabular}


(d) Policies

\section{Type of Management Policies}

Definite Plan to Improve Quality of Product

Conduct Regular Management Training

Maintain Employee Code of Conduct

Investigate Customer Complaints

Enforce Rules on Reporting, Closing \& Lunch Time

Hold Regular Management Meetings

Know and Enforce Employee Job Description

Delegate Responsibility to Qualified Employee

Keep Record of Accounts Receivable

Maintain Operating Budget of Activities

Maintain Revenue and Expenditure Plan

\begin{tabular}{|l|c|}
\hline & \% Response \\
\hline & 23.1 \\
\hline & 40 \\
\hline onch Time & 70.5 \\
\hline oyee & 68.9 \\
\hline & 68.4 \\
\hline & 26.3 \\
\hline & 61 \\
\hline & 41.6 \\
\hline & 71.6 \\
\hline
\end{tabular}

(e) Percentage Usage And Type Of Government Assistance Desired

\begin{tabular}{|c|c|c|c|}
\hline & Financial Assistance & Technical Assistance & Counseling, Monitoring and Management Assistance \\
\hline Percentage & 62.6 & 13.1 & 23.7 \\
\hline Gross Sales & $\mathrm{N} 430,891$ & $\mathrm{~N} 433,620$ & $\mathrm{~N} 503,244$ \\
\hline
\end{tabular}

(f) Ranking Of How Government Financial Assistance Will Be Used (1= highest Rank; 5= Least Rank; 0=nonresponse)

\begin{tabular}{|l|c|c|c|c|c|c|}
\hline & $\mathbf{1}$ & $\mathbf{2}$ & $\mathbf{3}$ & $\mathbf{4}$ & $\mathbf{5}$ & $\mathbf{0}$ \\
\hline Improve Technological Capability & 33.7 & 22.1 & 18.4 & 13.1 & 7.9 & 4.7 \\
\hline Gross Sales (N) & 523,305 & 427,083 & 403,900 & 463,400 & 330,600 & - \\
\hline & & & & & & \\
\hline Train Management and Other & & & & & & \\
\hline Employee & 15.3 & 18.9 & 24.7 & 27.4 & 7.4 & 6.3 \\
\hline Gross Sales (N) & 407,328 & 655,417 & 400,457 & 429,913 & 313,786 & - \\
\hline & & & & & & \\
\hline Pay Most or all Debt & 4.7 & 6.8 & 15.8 & 18.9 & 47.4 & 6.3 \\
\hline Gross Sales (N) & 493,889 & 572,462 & 422,000 & 456,250 & 444,506 & - \\
\hline & & & & & & \\
\hline Investigate Means to Improve & & & & & \\
\hline Product Quality & 10 & 28.4 & 20.5 & 20 & 14.7 & 6.3 \\
\hline Gross Sales (N) & & & & & & - \\
\hline Invest on New Plant \& & 517,079 & 364,935 & 466,974 & 486,763 & 526,339 & \\
\hline Equipment for Expansion & & & & & \\
\hline Gross Sales (N) & 32.1 & 18.4 & 14.2 & 14.2 & 13.7 & 7.4 \\
\hline
\end{tabular}

(g) Industry

\begin{tabular}{|l|c|c|}
\hline Arts and Crafts & 561,250 & 139,583 \\
\hline Fishing & - & - \\
\hline Pottery & - & 229,500 \\
\hline Cotton Weaving & 244,188 & 216,917 \\
\hline Mechanical & 522,083 & - \\
\hline Vegetable Oil Processing & - & 258,500 \\
\hline Petroleum Product & 835,000 & 235,000 \\
\hline Transportation & 684,792 & 212,000 \\
\hline Medical Center & 653,214 & 74,115 \\
\hline Fashion \& Dress Making & 220,731 & 92,773 \\
\hline Barber & 134,682 & 118,357 \\
\hline Carpentry & 361,071 & 327,400 \\
\hline Restaurant & 644,375 & 185,000 \\
\hline Animal \& Poultry & 434,500 & 159,927 \\
\hline Wholesale \& Retail & 359,645 & 56,250 \\
\hline Tailoring & 107,167 & 269,212 \\
\hline Other & 692,577 & \\
\hline
\end{tabular}


Table 2: Enterprise Performance By Owner And Industry Characteristics

\begin{tabular}{|c|c|c|c|}
\hline & Gross Sales (N) & Start-up Capital (N) & Employment \\
\hline & & (a) Gender of owner: & \\
\hline Male & 472,288 & 214,760 & 16 \\
\hline \multirow[t]{2}{*}{ Female } & 382,011 & 121,193 & 8 \\
\hline & & (b) Education of Owner: & \\
\hline Less than High School & 359,684 & 157,526 & 9 \\
\hline High School & 255,438 & 90,906 & 7 \\
\hline Diploma/Technical & 376,182 & 161,059 & 12 \\
\hline \multirow[t]{2}{*}{ University } & 552,086 & 241,043 & 17 \\
\hline & & (c) Age of Owner: & \\
\hline Under 30 Years & 354,808 & 82,135 & 4 \\
\hline $30-40$ & 338,831 & 176,554 & 9 \\
\hline $41-45$ & 519,938 & 222,115 & 17 \\
\hline $46-50$ & 552,036 & 283,571 & 23 \\
\hline $51-65$ & 647,475 & 139,600 & 20 \\
\hline \multirow[t]{2}{*}{ Over 65} & 383,333 & 200,838 & 6 \\
\hline & & (d) Tenure (Year of Formation) of Enterprise: & \\
\hline Before 1980 & 630,000 & 191,393 & 24 \\
\hline $1980-1985$ & 516,232 & 227,946 & 19 \\
\hline $1986-1990$ & 382,557 & 164,102 & 13 \\
\hline 1991-1995 & 598,583 & 175,319 & 14 \\
\hline \multirow[t]{2}{*}{ After 1995} & 500,000 & 207,257 & 9 \\
\hline & & (e) Size of Enterprise by Employment: & \\
\hline No Employees* & 250,529 & 112,559 & \\
\hline$<3$ & 213,903 & 88,742 & \\
\hline $3-6$ & 316,182 & 115,336 & \\
\hline $6-10$ & 469,239 & 284,674 & \\
\hline \multirow[t]{2}{*}{$>01$} & 894,231 & 317,423 & \\
\hline & & (f) Legal Form of Enterprise: & \\
\hline \multicolumn{4}{|l|}{ None Response } \\
\hline Sole Proprietor & 393,346 & 169,742 & 10 \\
\hline Partnership & 466,500 & 210,200 & 11 \\
\hline Limited Liability & 645,305 & 256,841 & 26 \\
\hline
\end{tabular}

Table 3: Performance By Type Of Management Intervention

\begin{tabular}{|l|c|c|c|c|}
\hline & \multicolumn{2}{|c|}{ Gross Sales } & \multicolumn{2}{c|}{ Employment Growth } \\
\hline & Use & Not Use & Use & Not Use \\
\hline Professional Services & 563,216 & 283,632 & 19 & 6 \\
\hline Has Plan to Improve Quality & 450,102 & 444,817 & 13 & 15 \\
\hline Regular Management Training & 627,658 & 327,969 & 23 & 8 \\
\hline Employee Code of Conduct & 516,877 & 281,202 & 16 & 8 \\
\hline Investigate Customer Comp. & 517,698 & 298,061 & 16 & 11 \\
\hline Record of Account Recv'ble & 514,316 & 276,875 & 15 & 8 \\
\hline Enforce Rules on Closing & 521,954 & 295,551 & 17 & 7 \\
\hline Hold Management Meetings & 718,400 & 365,162 & 27 & 10 \\
\hline Employee Job Description & 526,526 & 353,714 & 17 & 10 \\
\hline Delegate Responsibility & 569,146 & 506,583 & 18 & 10 \\
\hline Annual Plan of Rev. \& Exp. & 558,593 & 406,025 & 25 & 10 \\
\hline
\end{tabular}


Table 4: Results Of Interaction Analysis

\begin{tabular}{|l|c|c|c|}
\hline \multicolumn{1}{|c|}{ Interaction Variables } & \multicolumn{3}{c|}{ Average } \\
\hline & Gross Sales & Capital & Employment \\
\hline Large enterprise/Technology & 457,961 & 278,816 & 8 \\
\hline Large enterprise/Management & 497,500 & 302,500 & 8 \\
\hline Male-Owned/Technology & 469,754 & 221,662 & 15 \\
\hline Male-Owned/Management & 524,108 & 280,243 & 16 \\
\hline Female-Owned/Technology & 384,273 & 112,333 & 9 \\
\hline Female-Owned/Management & 525,400 & 141,350 & 11 \\
\hline Financial Assistance/Technology Orientation & 446,879 & 197,489 & 14 \\
\hline Financial Assistance/Management Orientation & 470,900 & 248,900 & 12 \\
\hline
\end{tabular}

\section{REFERENCES}

1. Bhalla, Ajit S. and Dilmus D. James (1991), Integrating New Technologies with Traditional Economic Activities in Developing Countries: An Evaluative Look at 'Technology Blending', Journal of Development Areas, Volume 24, July.

2. Biggs, Tyler (1999), A Micro-Econometric Evaluation Of The Mauritius Technology Diffusion Scheme (Tds), Discussion Papers, Regional Program On Enterprise Development, World Bank.

3. Chaves, Rodrigio and Susan Sanches (1997). Poverty, Entrepreneur, And Financial Markets In The Rural Areas Of Mexico, in Ramon Lopez And Alberto Valdes (Eds), Rural Poverty In Resources In Latin America, 15(1), 3-28 .

4. $\quad$ Cohen, Gary L. (1996) Women Entrepreneurs, Perspectives On Labor and Income, 8(1), 23-28.

5. Daly, John A (2002): Improving Technology Performance in Small and Medium Enterprises World Bank.

6. Dahlman, Carl J. and Larry E. Westphal (1981), Meaning Of Technological Mastry In Relation To The Transfer Of Technology, Annals Of The American Academy Of Political And Social Science, Vol.458, November.

7. Evans, David S. and Boyan Jovanovic (1989), An Estimated Model Of Entrepreneurial Choice Under Liquidity Constraints, Journal Of Political Economy, 97(4), 808-826.

8. Goldin, Ian, Halsey Rogers, and Nicholas Stern (2002) The Role and Effectiveness Of Development Assistance (Lessons From World Bank Experience), World Bank.

9. Little, I. M. D. (1988). Small Manufacturing Enterprises In Developing Countries, World Bank Economic Review, Vol.1, No. 2, Pages 203-235.

10. Mead, Donald M. (1991). Review Article: Small Enterprises and Development, Economic Development and Cultural Change, Vol. 39, January.

11. Oecd (1991), Enhancing Policy Effectiveness And Choice Oecd Development Center, Paris (April).

12. Otero, Maria and Elizabeth Rhyne (Eds) (1994), The New World Of Micro-Enterprise Finance (Building Health Financial Institutions For The Poor), Kumarian Press.

13. Pagan, Jose A. And Susan M. Sanches (2002) Explaining Gender Differences In Earnings In The MicroEnterprise Sector (Unpublished). 